\title{
Application of Matlab in Teaching of Statics in Theoretical Mechanics Course
}

\author{
Ming YANG \\ University of Science and Technology Liaoning, Anshan, China
}

\begin{abstract}
Two specific examples of statics illustrate the importance and convenience of introducing the numerical simulation in the theoretical mechanics course teaching. he same results were obtained through analytic method and computation program. We can use these results to testify human calculation. In class, we guide the student to use Matlab to solve problems in the theoretical mechanics computing processes. Not only can they verify the correctness of the traditional operation, they will also lay a solid foundation for the students future design and research work.
\end{abstract}

KEYWORD: Theoretical Mechanics, Statics, Matlab

\section{INTRODUCTION}

Matlab is the abbreviation of the Matrix Laboratory. It is a kind of interactive programming language based on matrix calculation. Mainly used for analysis and design of matrix calculating, controlling, and information processing[1]. It is convenient to use, simple and rich in content, operation efficiency, and easy to carry on the secondary development by the user. Compared with other computer languages, it is more suitable to the science and technology professional writing habits and ways of thinking, and greatly improves the efficiency of programming and debugging.

$\mathrm{Hu}$ jing discussed how to deal with nonlinear problems in theoretical mechanics[2]. Ao wengang [3] established the visual interface using Matlab in teaching of Theoretical Mechanics. It improves the students' perceptual knowledge in solving mechanical problems. The necessity of training the students to solving the problem by computer is analyzed in the teaching of theoretical mechanics[4], the main problems and causes of realizing the teaching concept are discussed, and the implementation of this teaching concept based on the mobile computing platform is proposed.

The papers above show that the necessity and importance of introducing information technology in teaching of theoretical mechanics course.

Two specific examples of statics illustrate the importance and convenience of introducing the numerical simulation in the theoretical mechanics course teaching[5]. In class, we guide the student to use Matlab to solve problems in the theoretical mechanics computing processes. Not only can they verify the correctness of the traditional operation, they will also lay a solid foundation for the students future design and research work.

\section{SIMPLIFY THE COPLANAR ARBITRARY FORCE SYSTEM}

A force system is composed by $\mathrm{N}$ force. Try to calculate the resultant of forces.

\subsection{Analytic method}

Through simplifying the force system to any point, we get the main vector and the principal moment.

$$
\begin{aligned}
& \vec{F}_{O}=\sum_{i=1}^{N} \vec{F}_{i}\left[F_{O x}, F_{O y}\right] \\
& M_{O}=\sum_{i=1}^{N}\left(\vec{r}_{i}-\vec{r}_{o}\right) \times \vec{F}_{i}=\sum_{i=1}^{N}\left(x_{i}-x_{o}\right) F_{y i}-\left(y_{i}-y_{o}\right) F_{x i}
\end{aligned}
$$

$\vec{r}_{i}$ is the radius vector of action point of $\vec{F}$, and
$\vec{r}_{o}$ is the radius vector of point $\mathrm{O}$. The main vector and the moment are transferred to $\mathrm{T}$ point. Assuming the moment is 0 , then the resultant force will be obtained.

Assuming

$$
M_{t}=\left(\vec{r}_{0}-\vec{r}_{t}\right) \times \vec{F}_{O}+M_{O}=0
$$


then

$\left(r_{0}-r_{t}\right)\left[\begin{array}{c}F_{O y} \\ F_{O x}\end{array}\right]=-M_{O}$

The point of the resultant force coordinate is $r_{t}=\frac{M_{O}}{\left[\begin{array}{l}F_{O y} \\ F_{O x}\end{array}\right]}+r_{0}$

$r_{t}$ is the radius vector of point $\mathrm{T}$.

\subsection{Computation program:}

Clear

$N=$ input('The number of input force $=$ ');

for $i=1: N$

$i ; F(i,:)=$ input('Component force of $F(i)$ $[F x(i), F y(i)]=')$;

$r(i,:)=$ input ('Coordinate of one $F(i)$ action point $\left.r(i)=[r x, r y]={ }^{\prime}\right)$;

end

ro=input('Center of reduction coordinate $r o=[x o, y o]=')$;

$F_{O}=\operatorname{sum}(F)$

for $\quad i=1: N$

$F(i, 1) *(r(i, 2)-r o(2))$;

$M(i)=F(i, 2) *(r(i, 1)-r o(1))-$

end

$\operatorname{Mo}=\operatorname{sum}(M)$

$r t=M o /[F o(2) ;-F o(1)]+r o$

Result:

The number of input force $=3$

Component force of $\mathrm{F}(\mathrm{i})$

$[\mathrm{Fx}(\mathrm{i}), \mathrm{Fy}(\mathrm{i})]=[2,3]$

Coordinate of one $\mathrm{F}(\mathrm{i})$ action point

$\mathrm{r}(\mathrm{i})=[\mathrm{rx}, \mathrm{ry}]=[-1,0]$

Component force of $\mathrm{F}(\mathrm{i})$

$[\mathrm{Fx}(\mathrm{i}), \mathrm{Fy}(\mathrm{i})]=[-4,7]$

Coordinate of one $\mathrm{F}(\mathrm{i})$ action point

$\mathrm{r}(\mathrm{i})=[\mathrm{rx}, \mathrm{ry}]=[1,-2]$

Component force of $\mathrm{F}(\mathrm{i})$

$[\operatorname{Fx}(\mathrm{i}), \mathrm{Fy}(\mathrm{i})]=[3,-4]$

Coordinate of one $\mathrm{F}(\mathrm{i})$ action point

$\mathrm{r}(\mathrm{i})=[\mathrm{rx}, \mathrm{ry}]=[1,2]$

Center of reduction coordinate

ro $=[\mathrm{xo}, \mathrm{yo}]=[-1,-1]$

$\mathrm{Fo}=$

16

$\mathrm{Mo}=$

$-9$

$\mathrm{rt}=$

$-2.5000-1.0000$

The same results were obtained through analytic method and computation program. We use the computation program to testify the correctness of analytic method. And we can also improve our master ability of computation software.

\section{THE EQUILIBRIUM OF FORCES}

Truss structure was shown in Fig. 1. Try to calculate the normal force of A, B, C.

Assuming

$\mathrm{P}_{1}=200 ; \quad \mathrm{P}_{2}=100 ; \quad \mathrm{L}_{1}=2 ; \quad \mathrm{L}_{2}=\operatorname{sqrt}(2) ;$

$\theta_{1}=30 *$ pi $/ 180 ; \theta_{2}=45 *$ pi $/ 180$;

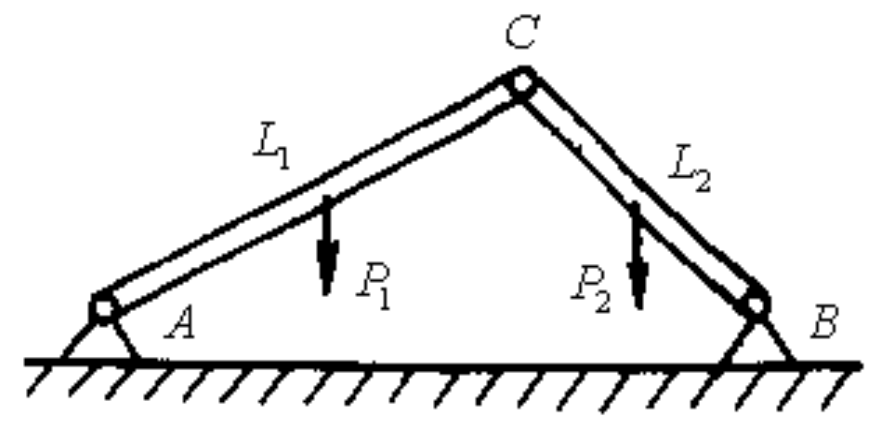

Fig. 1 truss structure

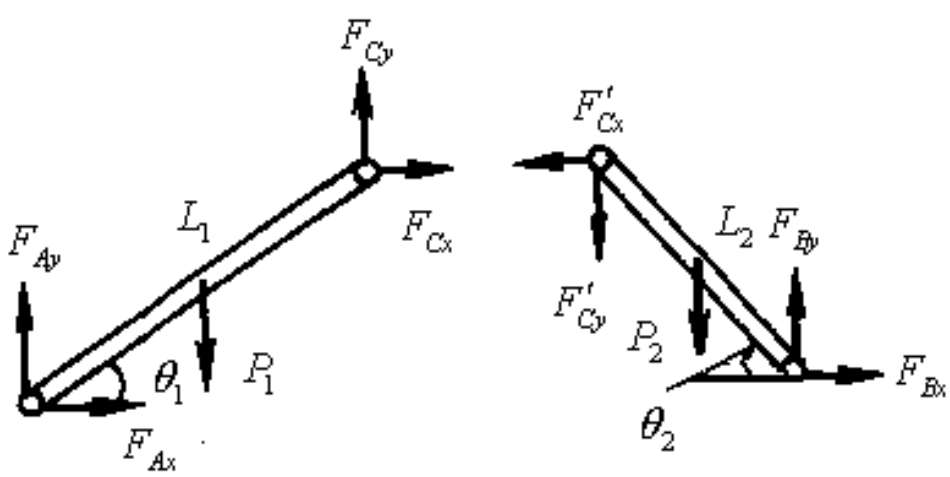

Fig. 2 force analysis

\subsection{Analytic method}

a. Force analyses were carried on in Fig. 2. From Fig. 2 , the equation of equilibrium of the force system was obtained as follows

$\sum F_{x}=0$

$F_{A x}+F_{c x}=0$

$\sum F_{y}=0$

$F_{A y}+F_{C y}-P_{1}=0$

$\sum M_{A}=0$

$F_{C y} L_{1} \cos \theta_{1}-F_{C x} L_{1} \sin \theta_{1}-\frac{1}{2} P_{1} L_{1} \cos \theta_{1}=0$

$\sum F_{x}=0$

$F_{B x}-F_{c x}^{\prime}=0$

$\sum F_{y}=0$

$F_{B y}-F_{C y}{ }^{\prime}-P_{2}=0$

$\sum M_{B}=0$

$F_{C y}{ }^{\prime} L_{2} \cos \theta_{2}+F_{C x}{ }^{\prime} L_{2} \sin \theta_{2}+\frac{1}{2} P_{2} L_{2} \cos \theta_{2}=0$ 


\subsection{Computation program:}

\section{Clear}

$P 1=200 ; P 2=100 ; L 1=2 ; L 2=\operatorname{sqrt}(2)$;

theta $1=30^{*}$ pi $/ 180$; theta $2=45^{*}$ pi $/ 180$;

$\% F=[F A x ; F A y ; F B x ; F B y ; F C x ; F C y]$

$A=[1,0,0,0,1,0 ; 0,1,0,0,0,1 ; 0,0,0,0$,-

$\sin ($ theta 1$), \cos ($ theta 1$) ; 0,0,1,0,-1,0 ; 0,0,0,1,0,-$

$1 ; 0,0,0,0, \sin ($ theta2), $\cos ($ theta2)]

$B=[0 ; P 1 ; P 1 / 2 *($ theta 1$) ; 0 ; P 2 ;-P 2 / 2 *($ theta 2$)]$

$F=A \mid B$;

$\operatorname{disp}\left(' F A x, F A y, F B x, F B y, F C x, F C y^{\prime}\right)$

$\operatorname{disp}\left(F^{\prime}\right)$

Result:

$\mathrm{A}=$

$\begin{array}{llllll}1.0000 & 0 & 0 & 0 & 1.0000 & 0 \\ 0 & 1.0000 & 0 & 0 & 0 & 1.0000 \\ 0 & 0 & 0 & 0 & -0.5000 & 0.8660 \\ 0 & 0 & 1.0000 & 0 & -1.0000 & 0 \\ 0 & 0 & 0 & 1.0000 & 0 & -1.0000 \\ 0 & 0 & 0 & 0 & 0.7071 & 0.7071\end{array}$

$\mathrm{B}=$

0

200.0000

52.3599

0

100.0000

$-32.2699$

$\begin{array}{llllll}\text { FAx, } & \text { FAy, } & \text { FBx }, & \text { FBy, } & \text { FCx, } & \text { FCy } \\ 73.5385 & 181.9975 & -73.5385 & 118.0025 & -73.5385 & 18.0025\end{array}$
The same results were obtained through analytic method and computation program.

\section{CONCLUSION}

Two specific examples of statics illustrate the importance and convenience of introducing the numerical simulation in the theoretical mechanics course teaching. The same results were obtained through analytic method and computation program.

We can use these results to testify human calculation ability. In class, we guide students to use Matlab to solve problems in theoretical mechanics computing processes. Not only can they verify the correctness of traditional operation, they will lay a solid foundation for students future design and research work.

\section{REFERENCES}

[1] Wang zhenglin, Liu ming. Master Matlab 7. Publishing house of electronics industry, Beijing, 2006.

[2] Hu jing, Peng fanglin, Guan jing, and Lu shengzhi. Matlab numerical solution of nonlinear problems in theoretical mechanics. College Physics, 2001, 20(10): 39-41.

[3] Ao wengang, Lin qin, Wang xin. Computer aided teaching of theoretical mechanics based on the Matlab. Mechanics in Engineering, 2013, 35(1):83-86.

[4] Zhang yongcun, Yu shen, Ma hongyan. Application of simulation in the teaching of theoretical mechanics computer numerical. Laboratory Science, 2013, 16(3):7481.

[5] Harbin industrial university theoretical mechanics teaching and research section. Theoretical Mechanics (7 Edition), Higher Education Press, Beijing, 2009. 